\title{
Integration of Virtual Manufacturing Technology and Course Teaching of Manufacturing Technology
}

\author{
En-guang $\mathrm{ZHANG}^{1, a,{ }^{*}}$ and $\mathrm{Li} \mathrm{WANG}^{2, b}$ \\ ${ }^{1,2}$ Department of mechanical and automotive engineering, Zhuhai College of Jilin \\ University, Zhuhai, China \\ ateamcenter@163.com, bwangli00019@163.com
}

Keywords: Virtual manufacturing, Fundamental of manufacturing technology, Integration, Interactive, Teaching reform.

\begin{abstract}
The fundamental of manufacturing technology is a basic course for the students majoring in mechanical engineering, the curriculum content of which is comprehensive and practical. Manufacturing technology is developing towards automation, and virtualization is one of its specific embodiment. In order to comply with the need of development of era, improve teaching quality, this paper integrated the virtual manufacturing (VM) technology and course teaching of manufacturing technology, reformed in teaching method and teaching content, and combined the basic theoretical knowledge of manufacturing and VM software such as $\mathrm{CAD} / \mathrm{CAE} / \mathrm{CAM}$ to realize product process planning and manufacturing etc., which are the essence of manufacturing process. At the same time, the interoperability and roaming ability of $\mathrm{CAD} / \mathrm{CAE} / \mathrm{CAM}$ software make the teaching method diversified and intuitive, which has certain significance.
\end{abstract}

\section{Introduction}

The fundamental of manufacturing technology is a basic course for the students majoring in mechanical engineering. Its purpose is to cultivate the students to master the basic rules of the metal cutting process, master the basic knowledge of machining, master machining methods and the selection of machine tools, cutting tools, fixtures and processing parameters, to enable the students to have the basic skills of process design and fixture design. It is an important professional basic course which is comprehensive and practical involving many contents.

Manufacturing industry is developing to automatization, mainly reflected in the following four aspects: virtualization, digital, green and intelligent. Among them, virtualization is a simulation operation of manufacturing by using a variety of advanced software technology in computer systems [1] to predict the product function, performance and machinability and other possible problems [2]. It is the highest level of $\mathrm{CAD} / \mathrm{CAE} / \mathrm{CAM}$ integration [3], and it is one of the key directions of manufacturing development.

\section{Course Offered}

In order to adapt to the development of manufacturing industry, the manufacturing technology curriculum in the university should keep pace with the times, that is to reform both in teaching methods and teaching contents. So it is urgent to fuse with virtual manufacturing technology. The mechanical design, manufacturing and automation major in Zhuhai college of Jilin University has carried out innovation and 
reform, and achieved good teaching results. In the curriculum, based on the strong genuine NX software foundation, our college set the CAD/CAE/CAM courses throughout the entire four years of college education, and the instruction is given step by step, which has become one of our key teaching features in mechanical design, manufacturing and automation major. The fundamental of manufacturing technology course is set in the junior year, when students have already mastered the related CAD/CAE/CAM software. So it has the necessary and sufficient conditions to combine the advanced virtual manufacturing technology with the basic theory course of manufacturing technology.

\section{Conditions for Ensuring the Product Quality}

All of the contents teached in the fundamental of manufacturing technology course are to achieve a high quality product with a certain function and meeting the performance requirements. The quality of the products includes two parts: the processing quality of the parts and the assembly quality of the products. And the machining quality of parts is the basis of ensuring the quality of products, and also the focus requirements of the manufacturing technology curriculum. To ensure the quality of products must meet the following requirements: product structure is reasonable; product manufacturing process is reasonable; the selection of manufacturing methods, machine tools, cutting tools, machining parameters, etc. are reasonable; the clamping scheme in the manufacturing process is reasonable; the clamping error is reasonable and etc. In the process of meeting these conditions, the VM technology can be integrated with the basic theory of manufacturing, in order to better ensure the quality of processing, improve production efficiency and reduce production costs.

\section{Integration of VM and manufacturing course}

From the point of view of ensuring the manufacturing quality, some examples are illustrated, which indicate that the integration of VM and manufacturing course can bring convenience to design and production, and can inject new vitality into classroom teaching.

\section{Application in Product Structure Processing}

In addition to meet the product performance, the mechanical product design should meet the requirements of manufacturing process, otherwise it may affect the production efficiency and product cost, and even cannot be produced in serious conditions [4]. The product structure processing is that the feasibility and economy of manufacture and maintenance under the premise of meeting the requirements of the products. Staff that lack of experience in design, especially the students, who are lack of actual production experience, are often thoughtless of manufacture. The product structures designed by them are often required to be modified after the process review. Computer aided design (CAD) in VM technology is a technology that can help designers to design by using computer and graphics devices [1]. Compared with 2D hand drawing, CAD makes the design and modification of complex geometry simpler, and provides a convenient opportunity for the structural modification of poor processing parts, which can greatly improve the work efficiency. 


\section{Application in the Teaching of Positioning Method}

When machining the work piece on the machine tool, in order to achieve the required size and shape and position tolerance of the surface processed, it need to locate the work piece correctly before starting the machine[4]. The correct position is determined according to the machining requirements of the work piece. Because the positioning ways needed by different parts and even different surfaces of the same part are not the same, it is difficult to completely make the physical teaching aids. So alone with the showing of text and pictures, the teaching effect is boring and it is obscure for students to understand. The VM technology, which is to use computer aided technology to design, process and assemble, has become more and more popular. For example, one side plus two pins positioning is one of the typical positioning methods, but with two long cylindrical pins, or two short cylindrical pins, or one long cylindrical pin and one short cylindrical pin, will have over-location phenomenon. In the process of teaching, it is always difficult for students to understand the concept. Using CAD technology can make students clearly understand the typical positioning method. Figure 1 shows the specific process. First of all, build an assembly model of one side and two short cylindrical pins, as shown in Figure 1.1. Then build a box as the locating work piece with a side and two holes, as shown in Figure 1.2. The following is the virtual assembly, which is easy to see the assembly interference caused by over-location, as shown in Figure 1.3 and Figure 1.4. However, the correct scheme should be a side plus a short cylindrical pin and an edge cutting pin, as shown in Figure 1.5, and the assemble should be as shown in Figure 1.6.

\section{Summary}

Because the VM software is interactive and roaming, teachers can give the class without heavy AIDS, and can expand the visual presentation range through the projector compared with traditional teaching aids. It benefits both the teachers and the students.

In short, the VM technology makes the course more intuitive and vivid. It can make virtual manufacturing before the parts are real machined in order to predict the manufacturing difficulties and grasp the accurate working hours, which can arrange the production schedule and management reasonably. It can improve production efficiency and reduce manufacturing cost. Integration of VM technology and course teaching of manufacturing technology is in line with the needs of the manufacturing industry to the development of automation. It is also the inevitable trend of the college teaching reform of the basic manufacturing technology. 


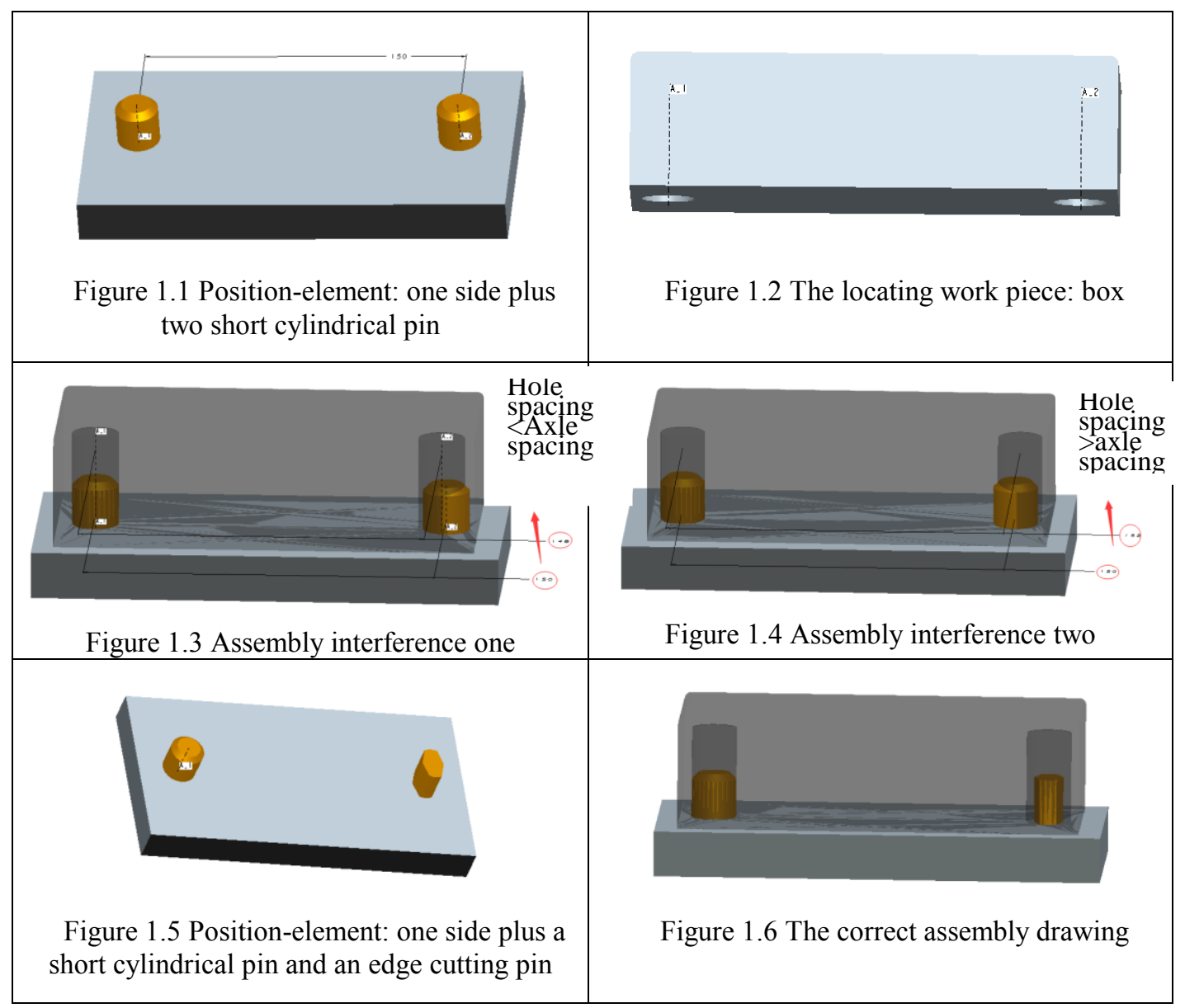

Figure 1 A typical positioning method: one side and two pins

\section{Acknowledgement}

This paper was financially supported by the excellent course project of "fundamental of manufacturing technology" in Guangdong province.

\section{References}

[1] H.J.Sun, Analysis of the combination of computer aided technology and mechanical design and manufacture, Private technology, 3(2016)84.

[2] W.S.Wan.Virtual Manufacturing Technology towards 21st Century. Mechatronics. 2(2004) 11-14.

[3] W.Q.Gao, Q.S.Yan, Z.Qin. Practice and Research in Teaching the Integrated Training of CAD/CAM/CAE Course, Journal of Guangdong University of Technology, Vol.4 Suppl(2004) 182-184.

[4] J.Y. Yu, Q.Zou, Fundamentals of Manufacturing Technology, third ed., China Machine Press, Beijing, 2009. 